\title{
A New Salmonella Serotype Isolated from Fowls in the Sudan
}

\author{
A. QUDDUS KHAN ${ }^{1}$ \\ Department of Bacteriology and Parasitology, Faculty of Veterinary Science, Khartoum, \\ Sudan
}

A new Salmonella serotype (Salmonella sp. serotype omdurman) was isolated in the Sudan from fowls with a history of reduced egg production and general deterioration of their physical condition. A description of the new serotype, whose antigenic structure is $6,7,14: \mathrm{d}: \mathrm{e}, \mathrm{n}, \mathrm{x}$, is given.

The author's backyard flock of Rhode Island Red chickens (six hens and one cockerel) showed a progressive decline in egg production and a gradual deterioration of their general physical condition. The six hens, which normally produced 20 eggs a week, eventually produced no eggs at all. One hen, in poorest condition, was sacrificed, and on postmortem examination misshapen and pedunculated ova were found. A motile salmonella was isolated from an ovary and from intestinal contents but not from heart blood, liver, or spleen. Swabs from the cloacas of all the remaining birds were taken at weekly intervals for 8 weeks and examined. The same salmonella was isolated intermittently from all of them. This organism, which belongs to a serotype not previously reported, is described below.

Morphology. Gram-negative, non-acidfast, non-sporulating rods which are motile by means of flagella.

Biochemical characters. The organism produced acid and gas in 1 day from arabinose, dulcitol, glucose, maltose, mannitol, rhamnose, sorbitol, trehalose, and xylose. It did not ferment adonitol, lactose, salicin, or sucrose. When tested by the method of Kauffmann and Petersen (2), the strain utilized citrate, $d$-tartrate, and mucate in 1 day. It did not attack $i$-tartrate or malonate. It produced lysine and ornithine decarboxylases in 1 day and arginine dihydrolase in 2 days.

The organism produced $\mathrm{H}_{2} \mathrm{~S}$ but not indole. It was methyl-red positive and Voges-Proskauer negative. It did not liquefy gelatin, failed to hydrolyze urea, and grew on Simmons' citrate agar but not in Moeller's KCN medium. The

\footnotetext{
${ }^{1}$ Present address: Faculty of Veterinary Science, Makerere University, Kampala, Uganda.
}

ONGP test as described by LeMinor and Ben Hamida (3) was negative.

Antigenic structure. The somatic antigens of the organism as determined with single-factor absorbed sera were $6,7,14$; therefore, it belonged to $\mathrm{O}$ group $\mathrm{C}_{4}$ in the KauffmannWhite schema.

The organism was diphasic. Its flagellar antigens were $d: e, n, x$. When the antibodies against both phases were added to Gard's medium (1) and inoculated with the strain under investigation, the growth did not spread, i.e., the antibodies completely immobilized the culture. Thus the complete antigenic structure of the strain was $6,7,14: d: e, n, x$.

Drug susceptibility. In vitro examination showed that the strain was very sensitive to ampicillin, cefalothin, chloramphenicol, colistin, gentamicin, nalidixin, nitrofurantoin, tetracycline, and bacterin but was resistant to penicillin and sulfonamide.

The organism was sent to Dr. Rohde of the National Salmonella-Zentrale, Hygienisches Institut, Hamburg, Germany, for confirmation of identity. Subsequently, Dr. Rohde sent the organism to L. LeMinor, Chief of the International Salmonella Centre, Pasteur Institute, Paris, France, who agreed that it was a new serotype.

The serotype is named Salmonella sp. serotype omdurman after Omdurman, the largest city in the Sudan, near which the organism was found.

I thank R. Rohde and L. LeMinor for confirming that the organism belongs to a new serotype and the latter for supplying biochemical data on the strain for comparison. 


\section{LITERATURE CITED}

1. Gard, S. 1938. Das Schwärmphänomen in der Salmonella Gruppe und seine practische Ausnützung. Z. Hyg. Infektionsk r. 120:615-619.

2. Kauffmann, F., and A. Petersen. 1956. The biochemical group and type differentiation of
Enterobacteriaceae by organic acids. Acta Pathol. Microbiol. Scand. 38:481-491.

3. LeMinor L., and F. B. Hamida. 1962. Avantages de la recherche de la $\beta$-galactosidase sur celle de la fermentation du lactose en milieu complexe dans le diagnostic bacteriologique, en particulier des Enterobacteriaceae. Ann. Inst. Pasteur 102:267-277. 